\title{
Enhanced Conductivity and Thermochromic Luminescence in Hydrogen Bond-Stabilized Columnar Liquid Crystals
}

\author{
Bin Mu, Yu Zhao, Xun Li, Xuhong Quan and Wei Tian*
}

Shanxi Key Laboratory of Macromolecular Science and Technology, MOE Key Laboratory of Material Physics and Chemistry under Extraordinary Conditions, School of Chemistry and Chemical Engineering, Northwestern Polytechnical University, Xi'an, 710072, China.

*E-mail: happytw_3000@nwpu.edu.cn

\section{Table of contents:}

1. Materials and Measurements

2. Crystallographic Data

3. Preparation of TCS based Quasi-Discotic LCs

4. Thermotropic LC Behaviors

5. Electrochemical and Electrical Conductivity Measurement

6. Spectroscopy Properties

7. Concentration Dependent Self-Assemblies and Luminescence Tuning Behavior

8. References for Supporting Information

\section{Materials and Measurements}

Materials. The synthesis of 3,4,5-trialkyloxybenzoic acids (3Cn) and 1,3,5-triformylbenzene were carried out according to our reported procedures. ${ }^{1}$ 4-Hydroxybenzyl cyanide $(>99 \%$, TCI) and 4 aminobenzyl cyanide $(>98 \%$, TCI) were used as received. All other chemical reagents were commercially available and used as received. 
Measurements. ${ }^{1} \mathrm{H}$ NMR spectra in solution were obtained from Bruker Avance 400 instruments. Multiplicities are denoted as follows: $\mathrm{s}=$ singlet, $\mathrm{d}=$ doublet, $\mathrm{t}=$ triplet, $\mathrm{q}=$ quartet, and $\mathrm{m}=$ multiplet. Fourier transform infrared spectra (FTIR) were recorded on a Nicolet iS50 infrared spectrometer. Matrix-assisted laser desorption/ionization time-of-flight mass spectrometry (MALDI-TOF-MS) was performed on a Bruker Autoflex II instrument, with $\alpha$-Cyano-4-hydroxycinnamic acid (CHCA) employed as the matrix substance. Differential scanning calorimetry (DSC) thermograms were recorded on a Netzsch DSC 214 system equipped with a cooling accessory and under nitrogen atmosphere at a flow rate of $20 \mathrm{~mL} \mathrm{~min}^{-1}$. Typically, about $5 \mathrm{mg}$ of the solid sample was encapsulated in a sealed aluminum pan with an identical empty pan as the reference with a heating or cooling rate of $10{ }^{\circ} \mathrm{C} \mathrm{min}^{-1}$. The polarized optical microscopy (POM) was adopted to characterize thermal transitions, observe and photograph textures with a Nikon E400POL microscope equipped with an Instec HCS302 hot and cold stage. X-ray diffraction (XRD) experiments were performed with Anton Paar SAXSess $\mathrm{mc}^{2}$ or SAXSpoint 2.0 small-angle X-ray scattering instruments. The scattering vector $q$ is defined as $4 \pi \sin \theta / \lambda$, where the wavelength $\lambda$ is $0.1542 \mathrm{~nm}$ of $\mathrm{Cu}-\mathrm{K}_{\alpha}$ radiation and $2 \theta$ is the scattering angle. Single crystal data for the TCS core were collected by using an Agilent Xcalibur Eos Gemini diffractometer. The conductivity of the samples was measured by using a gap-type top-contact planar two gold electrode device. Then current-voltage $(I-V)$ measurements of the devices were performed using a HongKong Nanoconnect semiconductor parameter analyzer. The electrochemical properties were measured using a CHI660E electrochemical workstation at a scan rate of $0.1 \mathrm{~V} \mathrm{~s}^{-1}$ under nitrogen in dichloromethane with tetrabutylammonium hexafluorophosphate (TBAPF6) as supporting electrolyte $(0.1 \mathrm{M})$. A three-electrode system (a glassy carbon working electrode, Pt counter electrode, and $\mathrm{Ag} / \mathrm{AgCl}$ reference electrode) was used in all cases. Scanning electron microscopy (SEM) images were obtained on a FEI Verios G4 instrument. Samples were prepared by drop casting on a cleaved silicon wafer and evaporation of the solvent, and then were coated with Au before imaging. Ultraviolet visible (UV-vis) absorption spectra were recorded on a Shimadzu UV-2550 spectrometer. Fluorescence spectra were recorded with a Hitachi F-4600 FL Spectrophotometer. The temperature dependent fluorescence spectra, absolute fluorescence quantum yield and time-resolved fluorescence lifetime experiments were recorded with an Edinburgh FLS980 transient steady-state fluorescence spectrometer. The absolute quantum yield was measured using an integrating sphere. The timeresolved lifetime was measured by using a $375 \mathrm{~nm}$ picosecond pulsed excitation source. 


\section{Crystallographic Data}

Table S1. Crystal data and structure refinement for the TCS core.

\begin{tabular}{|c|c|}
\hline Identification code & TCS \\
\hline $\mathrm{CCDC}$ & 1962647 \\
\hline Empirical formula & $\mathrm{C}_{33} \mathrm{H}_{21} \mathrm{~N}_{3}$ \\
\hline Formula weight & 459.53 \\
\hline Temperature $[\mathrm{K}]$ & 293(2) \\
\hline Crystal system & monoclinic \\
\hline Space group & $C 2 / c$ \\
\hline$a[\AA]$ & $13.4293(4)$ \\
\hline$b[\AA]$ & $14.3674(3)$ \\
\hline$c[\AA]$ & $26.5102(5)$ \\
\hline$\alpha\left[^{\circ}\right]$ & 90 \\
\hline$\beta\left[^{\circ}\right]$ & $99.258(2)$ \\
\hline$\gamma\left[^{\circ}\right]$ & 90 \\
\hline Volume $\left[\AA^{3}\right]$ & $5048.3(2)$ \\
\hline$Z$ & 8 \\
\hline$\rho_{\text {calc }}\left[\mathrm{g} \mathrm{cm}^{-3}\right]$ & 1.209 \\
\hline$\mu\left[\mathrm{mm}^{-1}\right]$ & 0.555 \\
\hline$F(000)$ & 1920.0 \\
\hline Crystal size $\left[\mathrm{mm}^{3}\right]$ & $0.22 \times 0.15 \times 0.12$ \\
\hline Radiation & $\mathrm{Cu} K_{\alpha}(\lambda=1.54184)$ \\
\hline $2 \theta$ range for data collection $\left[{ }^{\circ}\right]$ & 9.078 to 134.144 \\
\hline Index ranges & $-16 \leq h \leq 15,-16 \leq k \leq 17,-18 \leq l \leq 31$ \\
\hline Reflections collected & 10266 \\
\hline Independent reflections & $4510\left(R_{\text {int }}=0.0233, R_{\text {sigma }}=0.0271\right)$ \\
\hline Data/restraints/parameters & $4510 / 0 / 325$ \\
\hline Goodness-of-fit on $\mathrm{F}^{2}$ & 1.068 \\
\hline Final $R$ indexes $[I \geq 2 \sigma(I)]$ & $R_{1}=0.0494, w R_{2}=0.1313$ \\
\hline Final $R$ indexes [all data] & $R_{1}=0.0644, w R_{2}=0.1494$ \\
\hline Largest diff. peak/hole [e $\AA^{-3}$ ] & $0.12 /-0.19$ \\
\hline
\end{tabular}




\section{Preparation of TCS based Quasi-Discotic LCs}

The two series of TCS based star-shaped LC compounds 9Cn-ester-TCS and 9Cn-amide-TCS with varying peripheral chain lengths $(n)$ were prepared by two respective synthetic routes, thus we just take 9C10-ester-TCS and 9C10-amide-TCS as the examples for detailing the synthetic procedures.

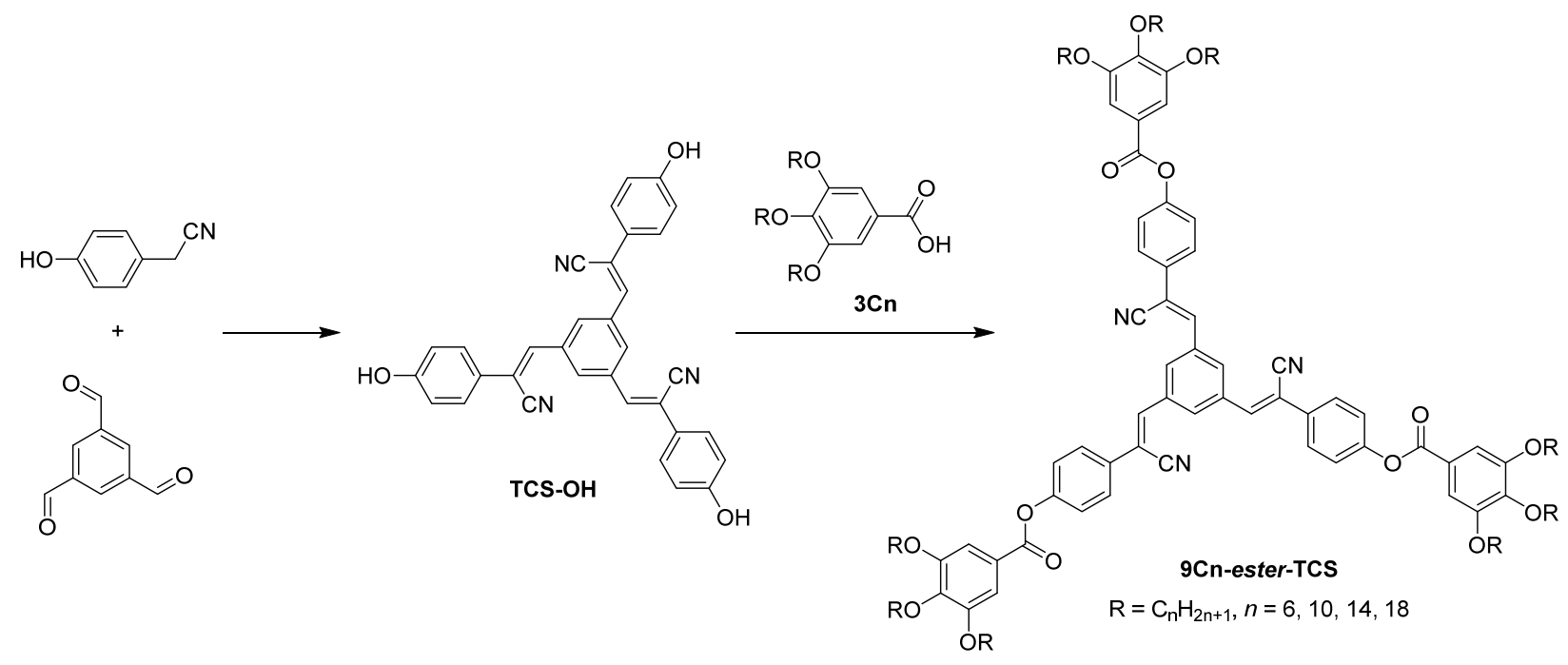

Scheme S1. Synthesis of 9Cn-ester-TCS

TCS-OH. A mixture of 1,3,5-triformylbenzene ( $0.9 \mathrm{~g}, 5.56 \mathrm{mmol})$, 4-hydroxybenzyl cyanide (2.36 g, $17.7 \mathrm{mmol})$, and potassium hydroxide $(1.87 \mathrm{~g}, 33.39 \mathrm{mmol})$ in $200 \mathrm{~mL}$ ethanol was refluxed at $80{ }^{\circ} \mathrm{C}$ overnight. The reaction mixture was cooled down to room temperature and was then poured into 200 $\mathrm{mL}$ water. After extraction with dichloromethane $(3 \times 50 \mathrm{~mL})$, the crude product was purified by silicagel column chromatography using mixed solvents of petroleum ether/ethyl acetate $(3: 1, \mathrm{v} / \mathrm{v})$ as the eluent to give a desired product (2.0 g) in light yellow solid. Yield 70\%. ${ }^{1} \mathrm{H}$ NMR (400 MHz, DMSO$\left.d_{6}\right): \delta=10.04(\mathrm{~s}, 3 \mathrm{H}), 8.31(\mathrm{~s}, 2 \mathrm{H}), 7.96(\mathrm{~s}, 3 \mathrm{H}), 7.65(\mathrm{~d}, 6 \mathrm{H}, J=8.0 \mathrm{~Hz}), 6.91(\mathrm{~d}, 6 \mathrm{H}, J=8.0 \mathrm{~Hz})$.

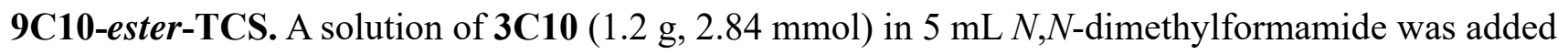
to a solution of TCS-OH (0.51 g, $0.92 \mathrm{mmol})$, 4-dimethylaminopyridine (96 mg, $0.79 \mathrm{~mol})$, and 1-(3dimethylaminopropyl)-3-ethylcarbodiimide $(0.23 \mathrm{~g}, 1.18 \mathrm{mmol})$ in $100 \mathrm{~mL}$ chloroform under icewater bath and then stirred at $70{ }^{\circ} \mathrm{C}$ overnight. The reaction mixture was cooled down to room temperature and was then poured into $200 \mathrm{~mL}$ water. After extraction with dichloromethane $(3 \times 50$ 
$\mathrm{mL}$ ), the crude product was purified by silica-gel column chromatography using mixed solvents of petroleum ether/ethyl acetate $(10: 1, \mathrm{v} / \mathrm{v})$ as the eluent to give a desired product $(1.2 \mathrm{~g})$ in light yellow solid. Yield 76\%. ${ }^{1} \mathrm{H}$ NMR (400 MHz, chloroform- $\left.d_{1}\right): \delta=8.46(\mathrm{~s}, 3 \mathrm{H}), 7.82(\mathrm{~d}, 6 \mathrm{H}, J=8.0 \mathrm{~Hz}), 7.69$ $(\mathrm{s}, 3 \mathrm{H}), 7.45(\mathrm{~s}, 6 \mathrm{H}), 7.36(\mathrm{~d}, 6 \mathrm{H}, J=8.0 \mathrm{~Hz}), 4.09(\mathrm{~m}, 18 \mathrm{H}), 1.93-1.20(\mathrm{~m}, 144 \mathrm{H}), 0.91(\mathrm{t}, 27 \mathrm{H}, J=$ $6.8 \mathrm{~Hz})$.
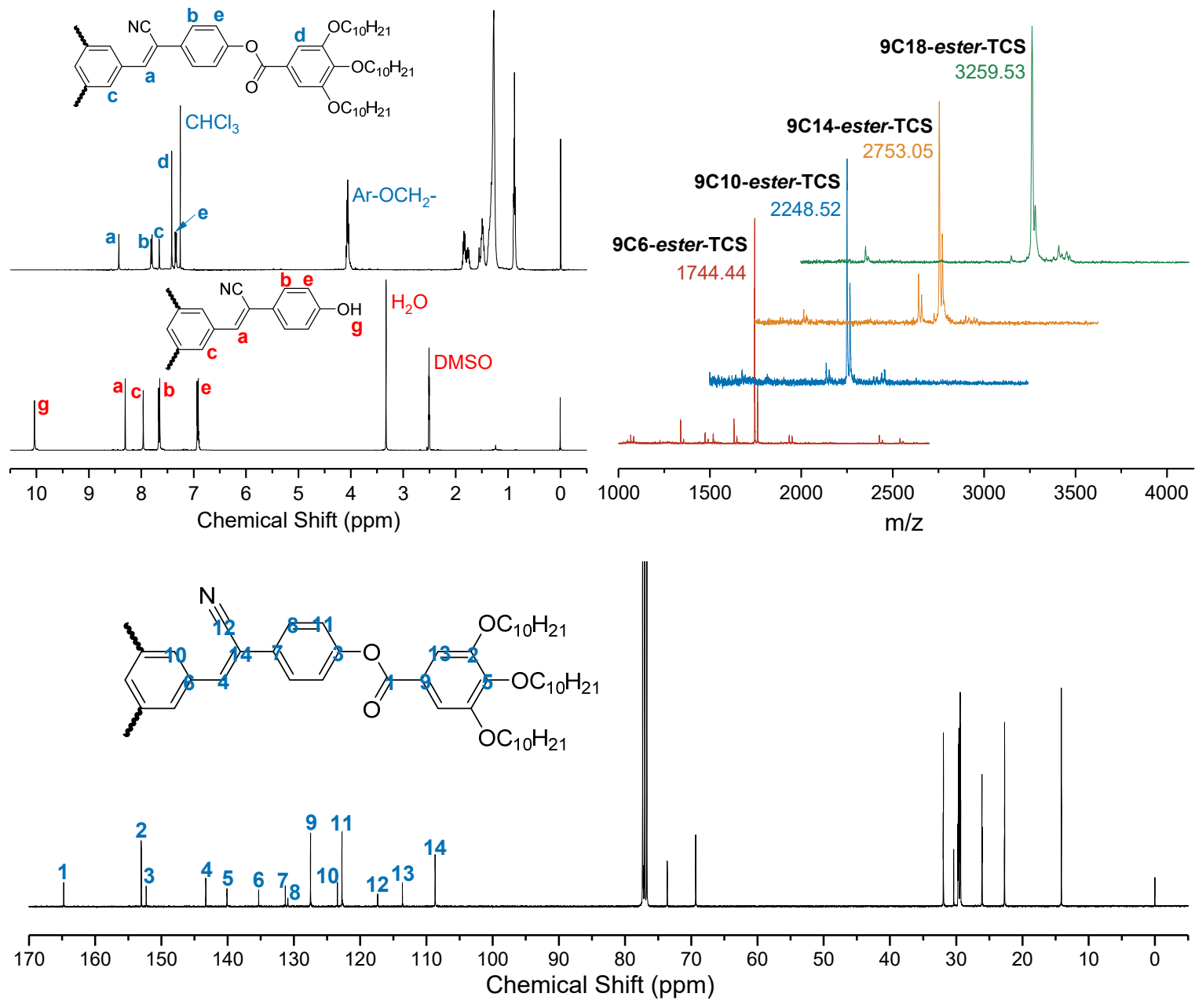

Figure S1. Molecular characterization of 9Cn-ester-TCS and their precursor TCS-OH by ${ }^{1} \mathrm{H}$ NMR (left), ${ }^{13} \mathrm{C}$ NMR (bottom) and MALDI-TOF-MS (right). 


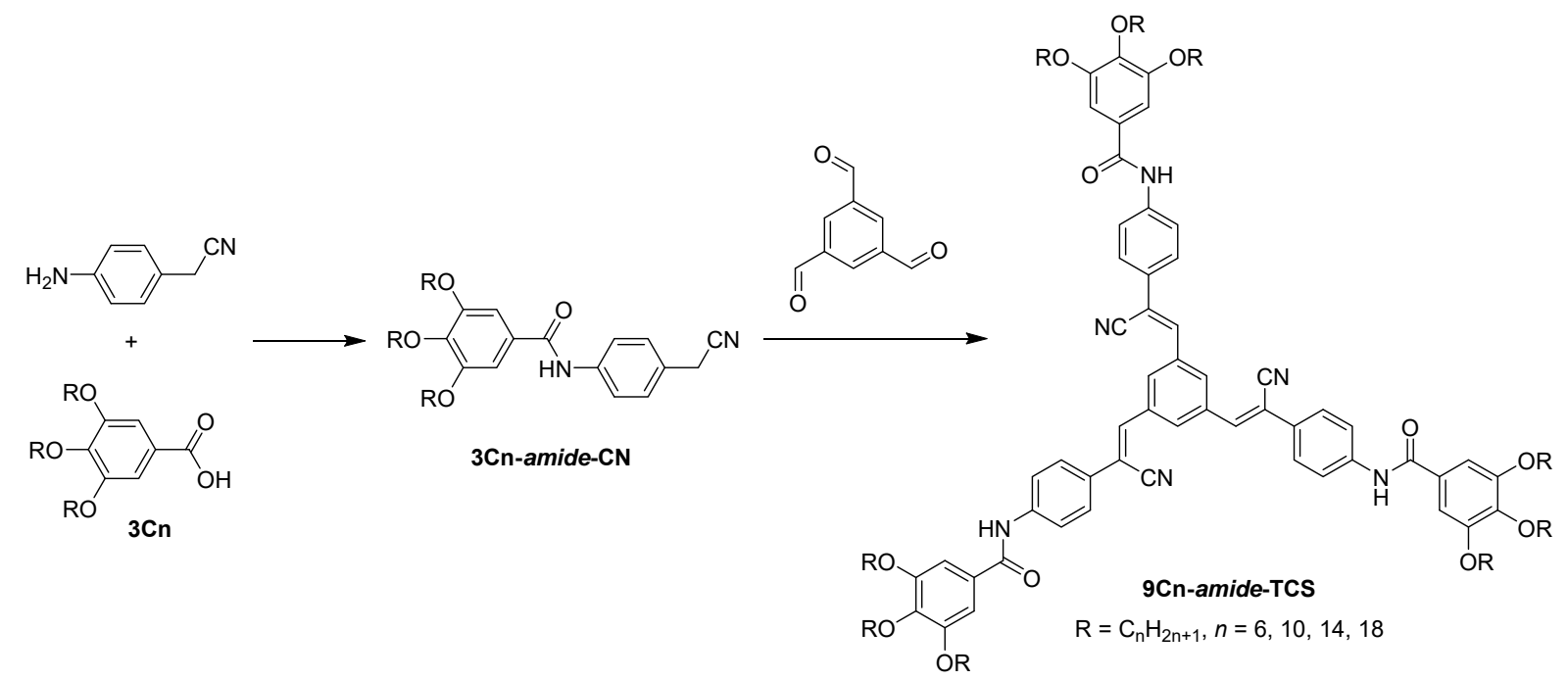

Scheme S2. Synthesis of 9Cn-amide-TCS

3C10-amide-CN. $N, N$-Diisopropylcarbodiimide $(0.54 \mathrm{~g}, 4.3 \mathrm{mmol})$ was added to a solution of $3 \mathrm{C10}$ (0.36 g, $0.86 \mathrm{mmol})$, 4-aminobenzyl cyanide ( $0.14 \mathrm{~g}, 1.04 \mathrm{~mol})$, and $N, N$-dimethylpyridin-4-amine 4methylbenzenesulfonate $(0.1 \mathrm{~g}, 0.34 \mathrm{mmol})$ in a mixed solvent of $10 \mathrm{~mL}$ THF and $40 \mathrm{~mL}$ dichloromethane under ice-water bath. The reaction mixture continued to stir for $24 \mathrm{~h}$ and then $50 \mathrm{~mL}$ water was added. After extraction with dichloromethane $(3 \times 50 \mathrm{~mL})$, the crude product was purified by silica-gel column chromatography using mixed solvents of petroleum ether/ethyl acetate $(10: 1, \mathrm{v} / \mathrm{v})$ as the eluent to give a desired product $(0.44 \mathrm{~g})$ in white solid. Yield $96 \%$. ${ }^{1} \mathrm{H}$ NMR (400 MHz, chloroform- $\left.d_{1}\right): \delta=7.76(\mathrm{~s}, 1 \mathrm{H}), 7.67(\mathrm{~d}, 2 \mathrm{H}, J=8.0 \mathrm{~Hz}), 7.34(\mathrm{~d}, 2 \mathrm{H}, J=8.0 \mathrm{~Hz}), 7.06(\mathrm{~s}, 2 \mathrm{H}), 4.06$ $(\mathrm{m}, 6 \mathrm{H}), 3.77(\mathrm{~s}, 2 \mathrm{H}), 1.91-1.21(\mathrm{~m}, 48 \mathrm{H}), 0.90(\mathrm{t}, 9 \mathrm{H}, J=6.8 \mathrm{~Hz})$.

9C10-amide-TCS. 40\% Tetrabutylammonium hydroxide solution in methanol $(0.5 \mathrm{~mL})$ was added to a solution of 1,3,5-triformylbenzene $(0.55 \mathrm{~g}, 0.34 \mathrm{mmol})$ and $\mathbf{3 C 1 0}$-amide-CN $(0.6 \mathrm{~g}, 1.12 \mathrm{mmol})$ in $50 \mathrm{~mL}$ ethanol at $55{ }^{\circ} \mathrm{C}$. After reaction was completed monitored by TLC, the reaction mixture was allowed to cool to room temperature. The desired product $(0.45 \mathrm{~g})$ in light yellow solid was collected by a simple filtration. Yield 77\%. ${ }^{1} \mathrm{H}$ NMR (400 MHz, chloroform- $\left.d_{1}\right): \delta=8.40(\mathrm{~s}, 3 \mathrm{H}), 7.94(\mathrm{~s}, 3 \mathrm{H})$, $7.77(\mathrm{q}, 12 \mathrm{H}, J=8.8 \mathrm{~Hz}), 7.63(\mathrm{~s}, 3 \mathrm{H}), 7.10(\mathrm{~s}, 6 \mathrm{H}), 4.07(\mathrm{~m}, 18 \mathrm{H}), 1.91-1.21(\mathrm{~m}, 144 \mathrm{H}), 0.91(\mathrm{t}, 27 \mathrm{H}$, $J=6.8 \mathrm{~Hz})$. 

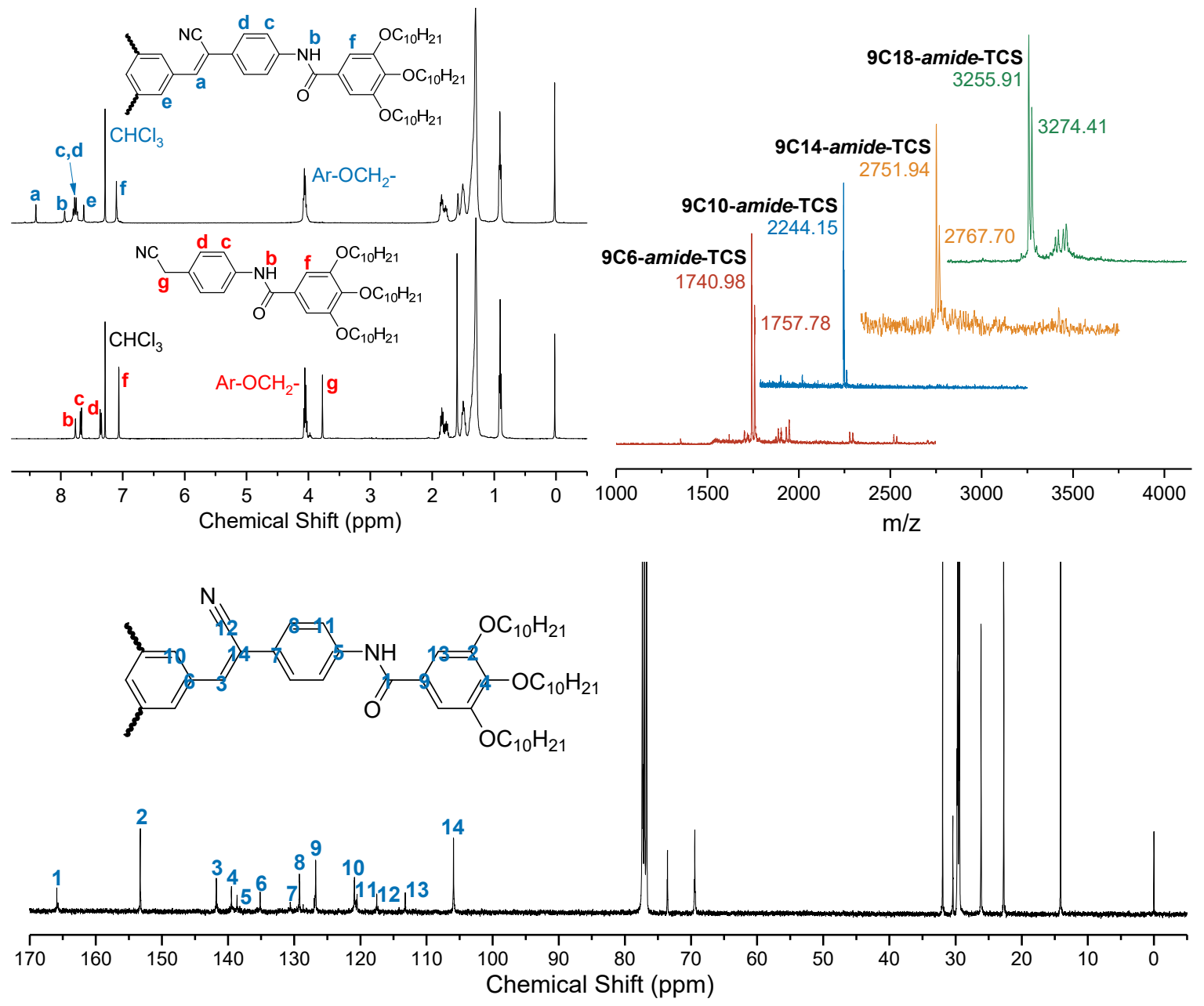

Figure S2. Molecular characterization of 9Cn-amide-TCS and their precursor $\mathbf{3 C n}$-amide-CN by ${ }^{1} \mathrm{H}$ NMR (left), ${ }^{13} \mathrm{C}$ NMR (bottom) and MALDI-TOF-MS (right). 


\section{Thermotropic LC Behaviors}
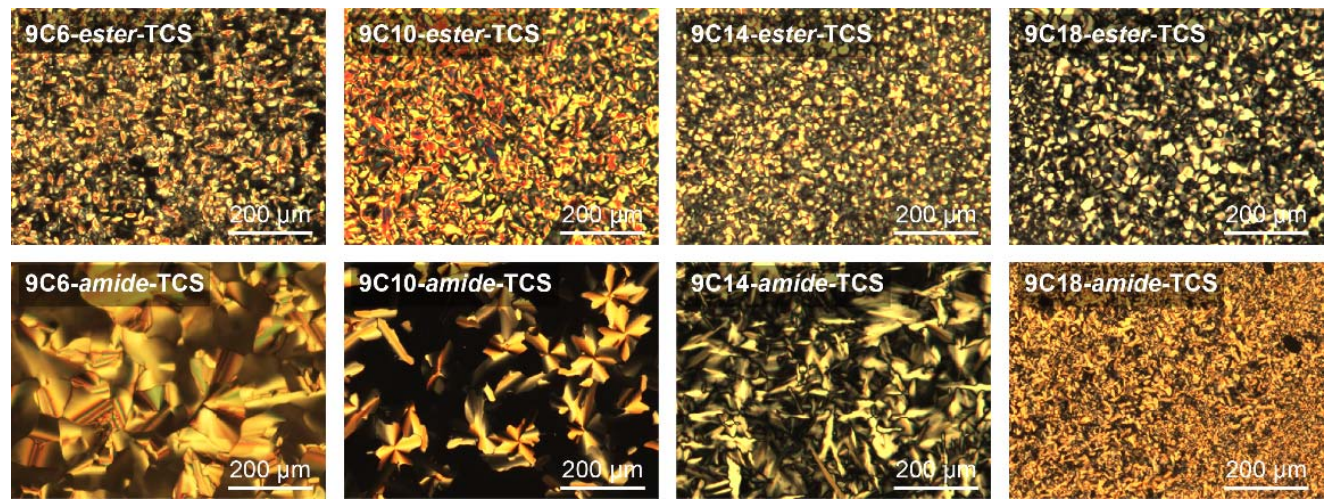

Figure S3. POM images collected from 9Cn-ester-TCS (top) and 9Cn-amide-TCS (bottom) in their liquid crystal mesophases.
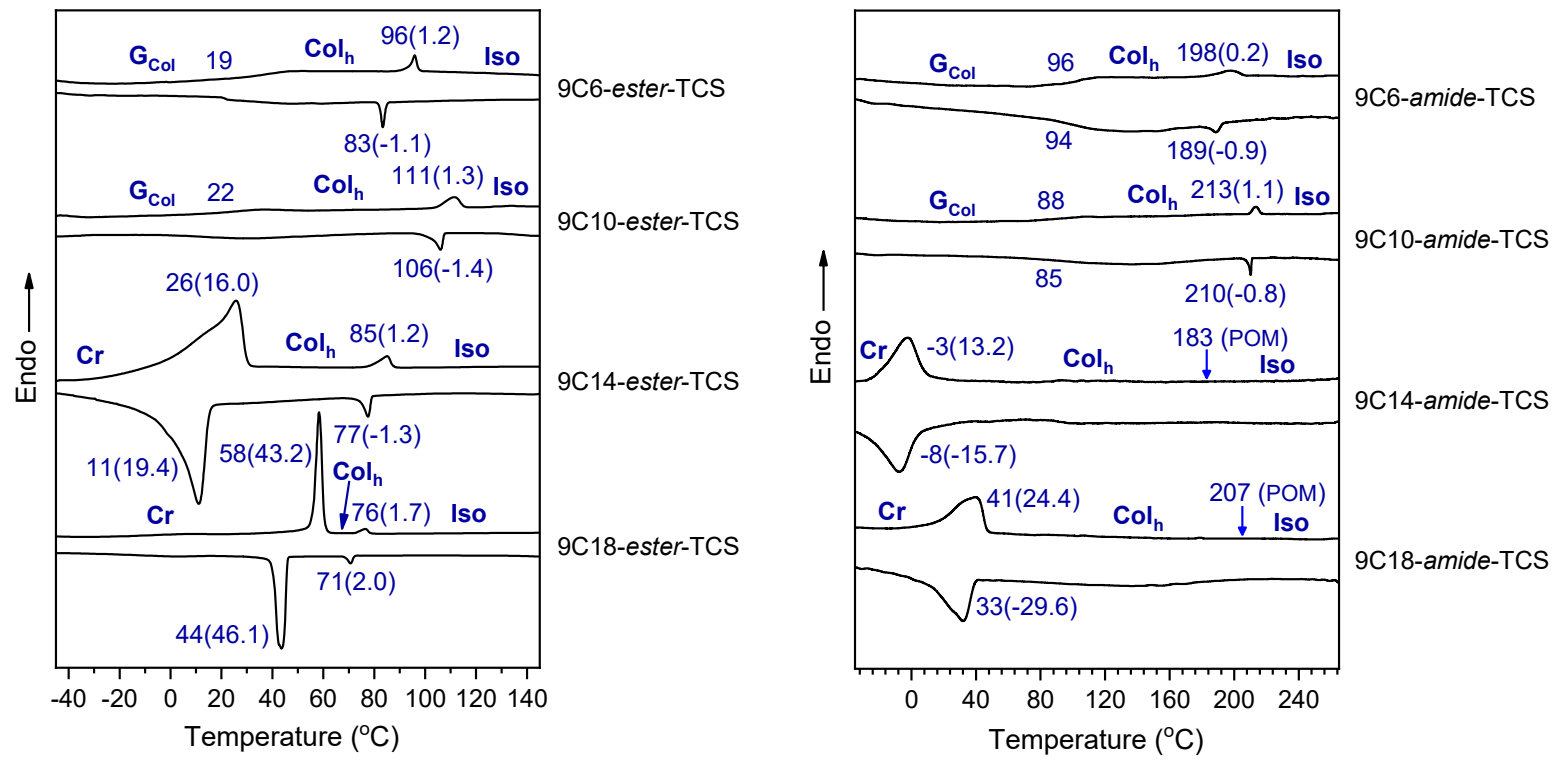

Figure S4. DSC traces collected from 9Cn-ester-TCS (left) and 9Cn-amide-TCS (right) during their second heating and first cooling process, indicating with transition peak temperature (in ${ }^{\circ} \mathrm{C}$ ), and associated enthalpy changes (in parentheses, in $\mathrm{J} \mathrm{g}^{-1}$ ). Abbreviations: $\mathrm{G}_{\mathrm{Col}}=$ Glassy columnar phase, $\mathrm{Cr}=$ Crystalline solid; $\mathrm{Col}_{\mathrm{h}}=$ Hexagonal columnar mesophase; Iso = Isotropic liquid. 

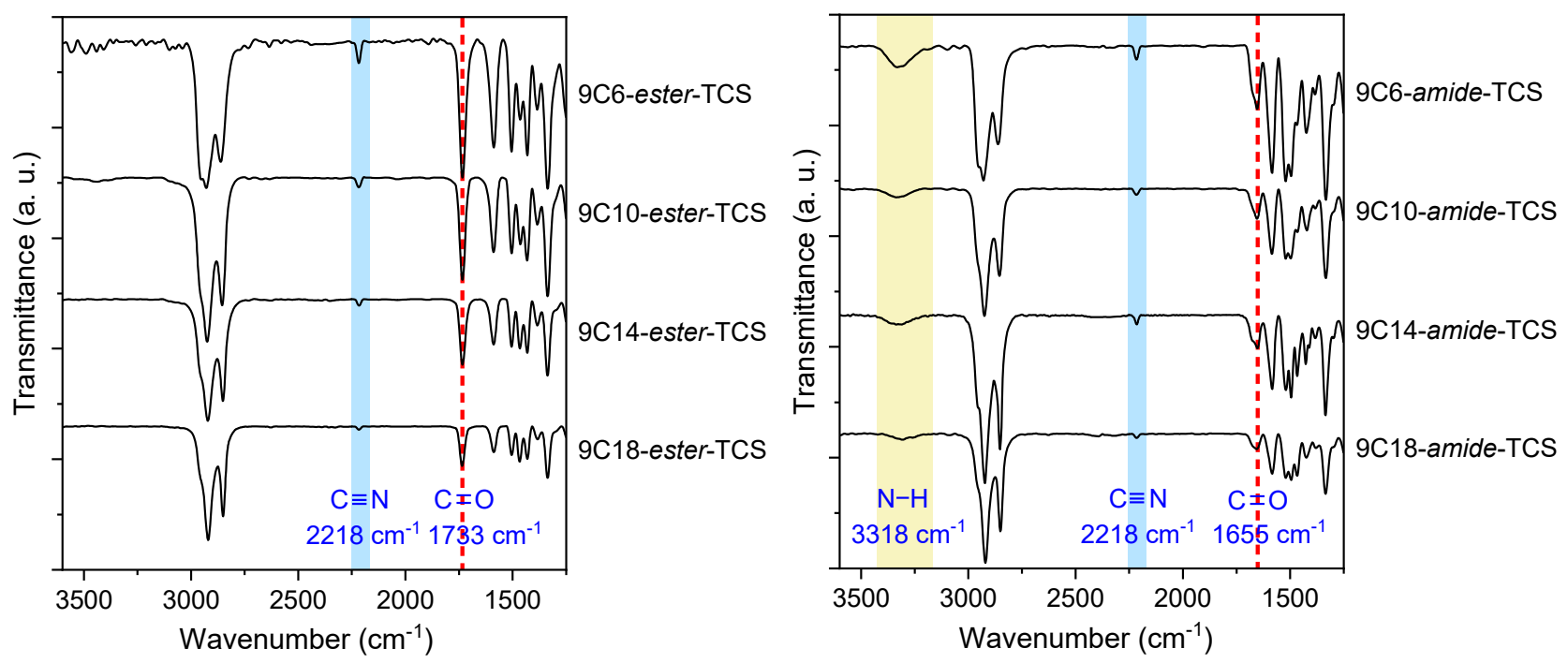

Figure S5. FTIR spectra collected from 9Cn-ester-TCS (left) and 9Cn-amide-TCS (right) at room temperature.
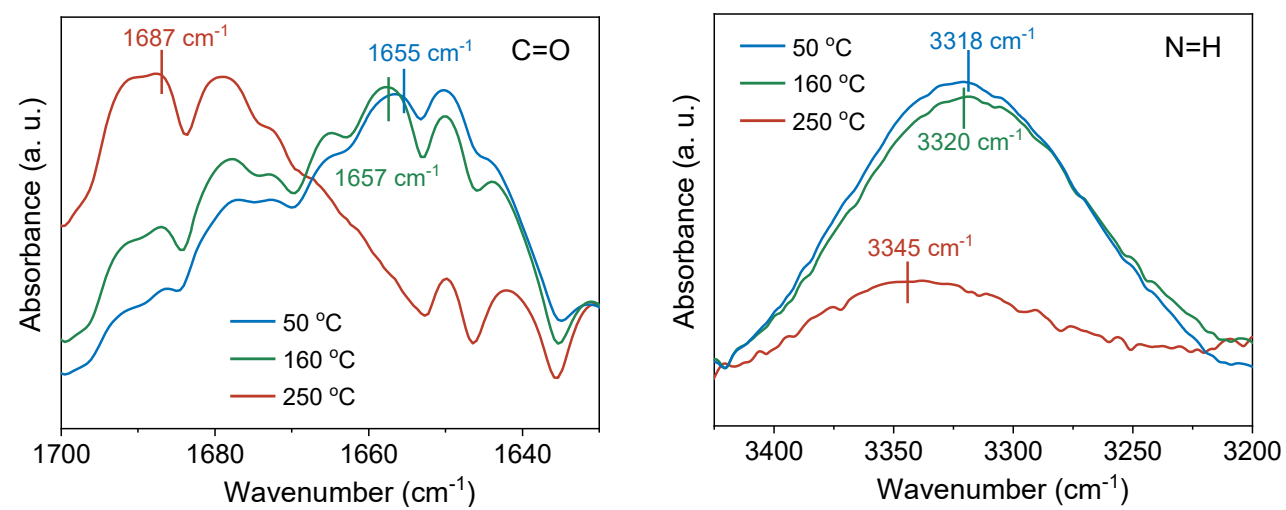

Figure S6. Temperature dependent FTIR spectra of 9C6-amide-TCS at indicated temperatures. Only the relevant amide $\mathrm{C}=\mathrm{O}$ and $\mathrm{N}-\mathrm{H}$ vibrations are shown (left) between 1700 and $1630 \mathrm{~cm}^{-1}$, and (right) between 3425 and $3200 \mathrm{~cm}^{-1}$, respectively. 

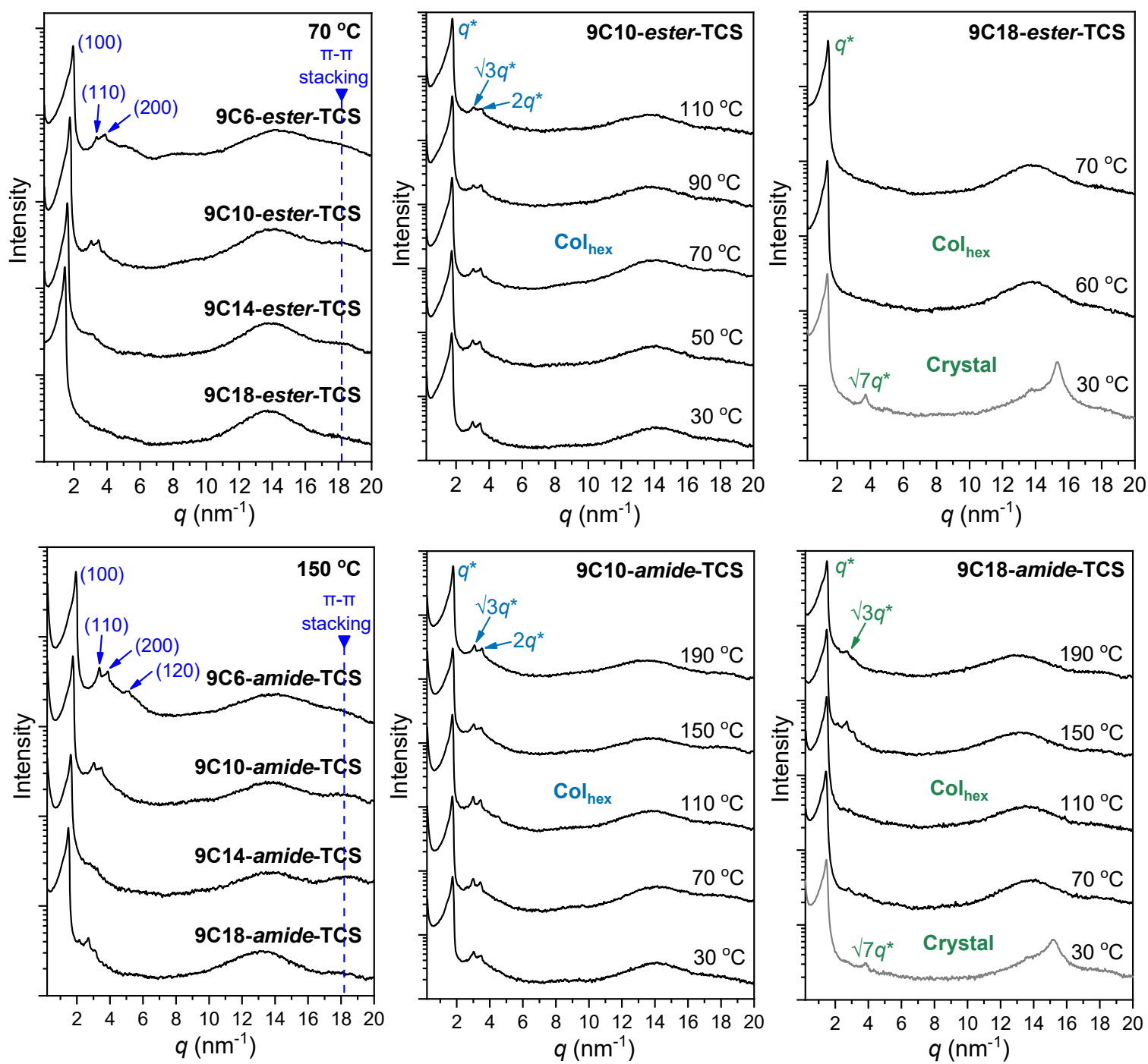

Figure S7. Variant temperature XRD profiles collected from 9Cn-ester-TCS and 9Cn-amide-TCS at indicated temperatures with proposed indexing and phase assignment.

Table S2. Lattice parameters of 9Cn-ester-TCS and 9Cn-amide-TCS deduced from XRD analysis.

\begin{tabular}{|c|c|c|c|c|c|}
\hline \multirow{2}{*}{ Compounds } & \multicolumn{4}{|c|}{ Lattice parameter $(\mathrm{nm})^{a}$} & \multirow{2}{*}{$\begin{array}{l}\text { CPK molecular model for } \\
\text { 9C6-amide-TCS }\end{array}$} \\
\hline & $n=6$ & $n=10$ & $n=14$ & $n=18$ & \\
\hline $\begin{array}{l}\text { 9Cn-ester-TCS } \\
\text { (at } 70^{\circ} \mathrm{C} \text { ) }\end{array}$ & $a=3.76$ & $a=4.16$ & $a=4.52$ & $a=5.02$ & \\
\hline $\begin{array}{c}\text { 9Cn-amide-TCS } \\
\text { (at } 150^{\circ} \mathrm{C} \text { ) }\end{array}$ & $a=3.74$ & $a=4.13$ & $a=4.48$ & $a=4.97$ & \\
\hline \multicolumn{6}{|c|}{$\begin{array}{l}{ }^{a} \text { The lattice parameter is calculated as } a=2 d_{(100)} / \sqrt{ } 3 \text {, where } d_{(100)} \\
\text { is the reciprocal spacing of the (100) diffraction peak in the XRD } \\
\text { pattern typical for a hexagonal columnar mesophase. }\end{array}$} \\
\hline
\end{tabular}


Table S3. The observed diffraction peaks, and their $d$-spacings, intensities, multiplicities, and phases used in the reconstruction of electron densities.

\begin{tabular}{ccccccc}
\hline Compounds & $(h k)$ & $d_{\text {obs }}(\mathrm{nm})$ & $d_{\text {cal }}(\mathrm{nm})$ & Intensity & Multiplicity & Phase \\
\hline \multirow{4}{*}{ 9C6-amide-TCS } & $(10)$ & 3.24 & 3.24 & 100 & 6 & $\pi$ \\
& $(11)$ & 5.61 & 5.61 & 5.7 & 6 & $\pi$ \\
& $(20)$ & 6.48 & 6.48 & 4.3 & 6 & 0 \\
\hline \multirow{3}{*}{ 9C6-ester-TCS } & $(10)$ & 3.26 & 3.26 & 100 & 6 & 0 \\
& $(11)$ & 5.65 & 5.65 & 5.1 & 6 & $\pi$ \\
& $(20)$ & 6.52 & 6.52 & 7.7 & 6 & 0 \\
\hline
\end{tabular}
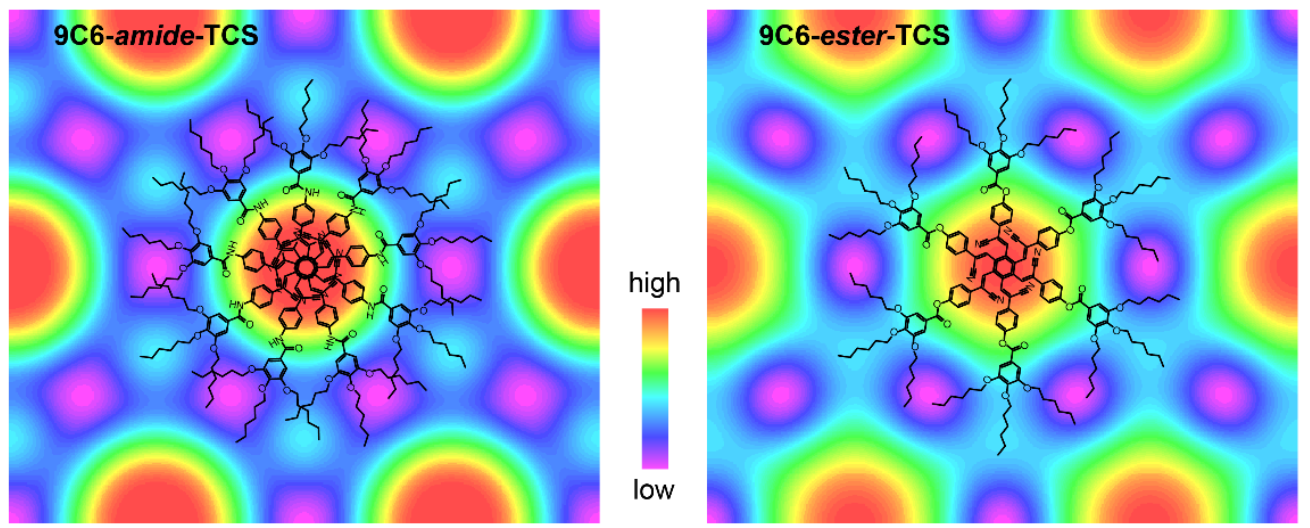

Figure S8. The possible arrangement of molecules inside a column for the assembled columns, where helical stacking is the most plausible mode with respect to the electron density map in a circular shape for 9C6-amide-TCS, while it seems more reasonable to adopt a staggered stacking to generate the hexagonally distributed medium electron density area for 9C6-ester-TCS. 

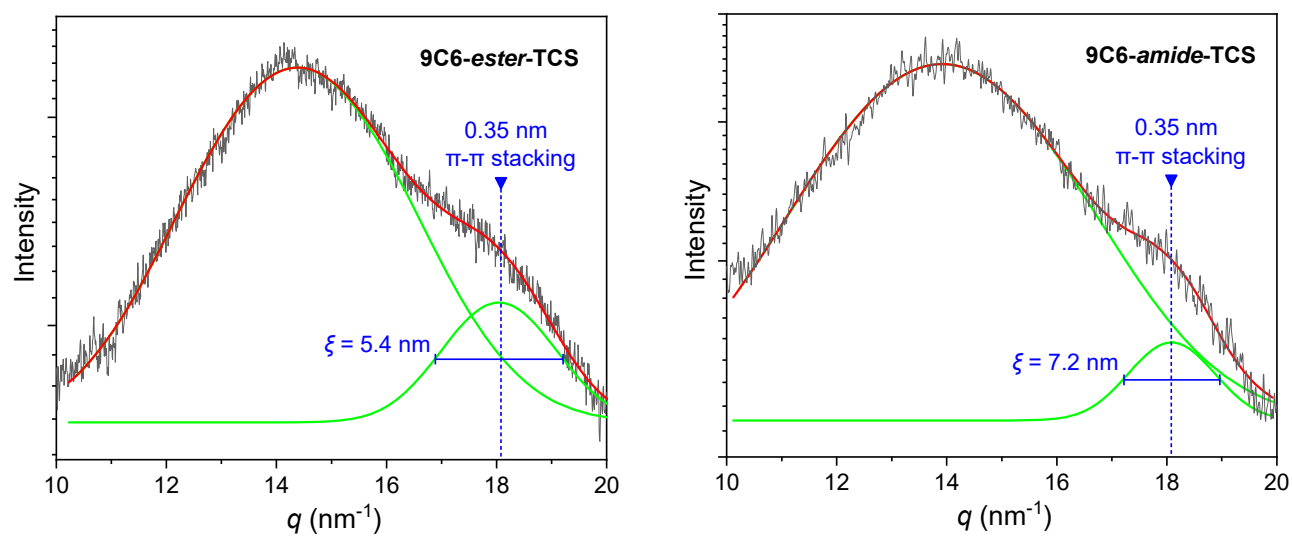

Figure S9. The representative diffraction plot at wide-angle region with peak deconvolution. The correlation length $\xi$ is estimated from the full width at half-maximum (fwhm).

\section{Electrochemical and Electrical Conductivity Measurement}
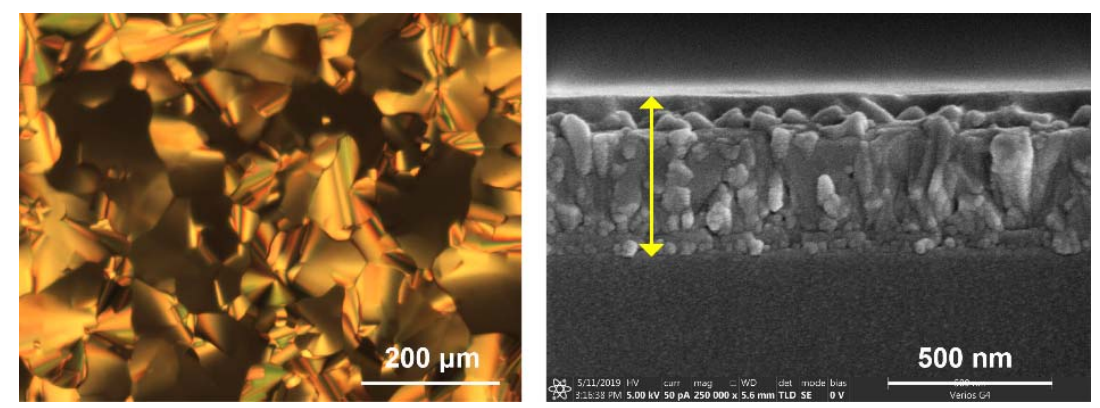

Figure S10. Characterization of the spin-coated film of 9C6-amide-TCS in $I-V$ measurement. (left) The corresponding POM image indicating a polydomain organization. (right) Cross-sectional SEM image showing the film thickness of about $0.5 \mu \mathrm{m}$.
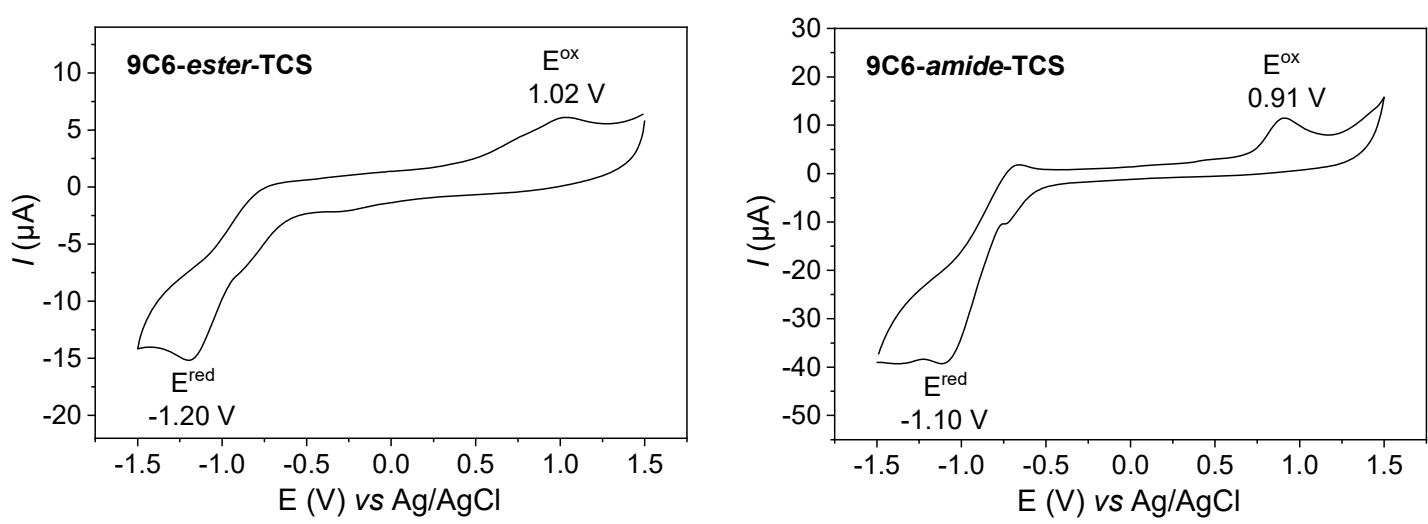

Figure S11. Cyclic voltammogram of 9C6-ester-TCS and 9C6-amide-TCS in dichloromethane solution. The potential values used for the estimation of the energy levels are indicated. 
Table S4. Electrical conductivity of 9Cn-ester-TCS and 9Cn-amide-TCS determined by $I-V$ measurement.

\begin{tabular}{ccccc}
\hline \multirow{2}{*}{ Compounds } & \multicolumn{4}{c}{ Conductivity $\left(\mathrm{S} \mathrm{m}^{-1}\right)$} \\
& $n=6$ & $n=10$ & $n=14$ & $n=18$ \\
\hline 9Cn-ester-TCS & $2.50 \times 10^{-4}$ & $2.02 \times 10^{-4}$ & $1.64 \times 10^{-4}$ & $1.26 \times 10^{-4}$ \\
9Cn-amide-TCS & $1.20 \times 10^{-3}$ & $1.06 \times 10^{-3}$ & $1.00 \times 10^{-3}$ & $0.93 \times 10^{-3}$ \\
\hline
\end{tabular}

\section{Spectroscopy Properties}
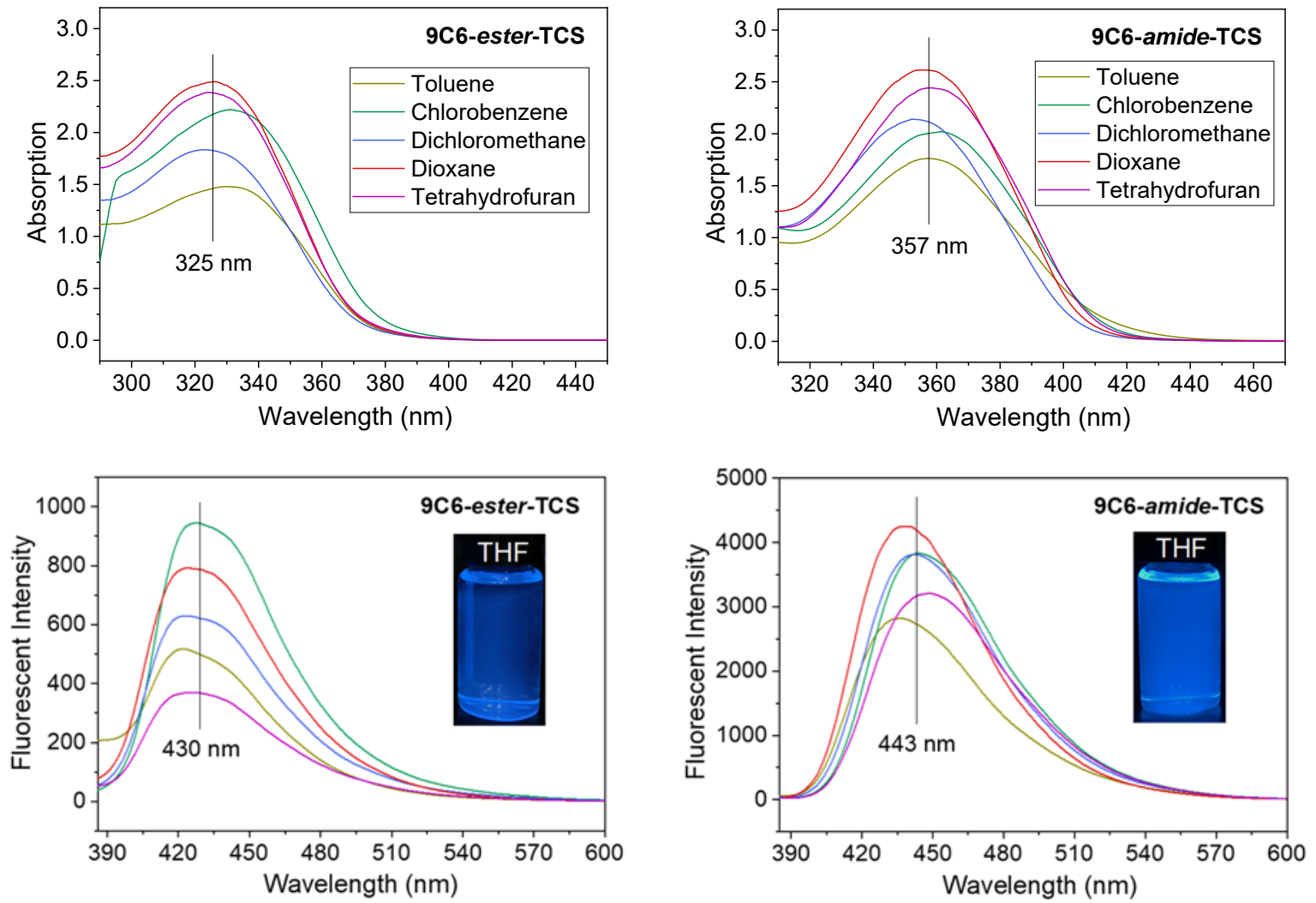

Figure S12. UV-vis absorption $\left(c=10^{-5} \mathrm{~mol} \mathrm{~L}^{-1}\right)$ and fluorescent emission spectra $\left(c=10^{-7} \mathrm{~mol} \mathrm{~L}^{-1}\right)$ of 9C6-ester-TCS and 9C6-amide-TCS in different solvents. 

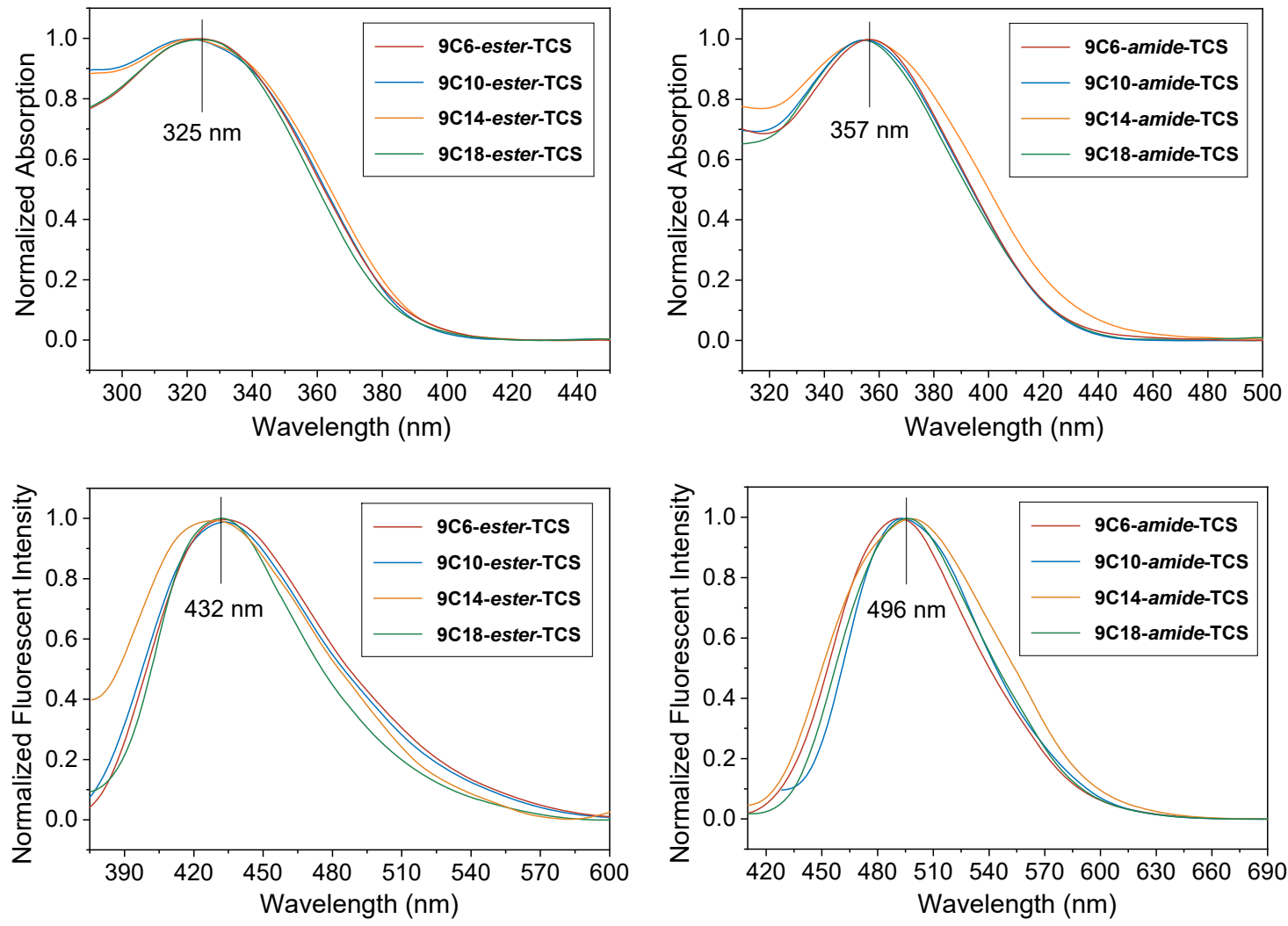

Figure S13. Normalized absorption and emission spectra of 9Cn-ester-TCS and 9Cn-amide-TCS in as-prepared solid state.

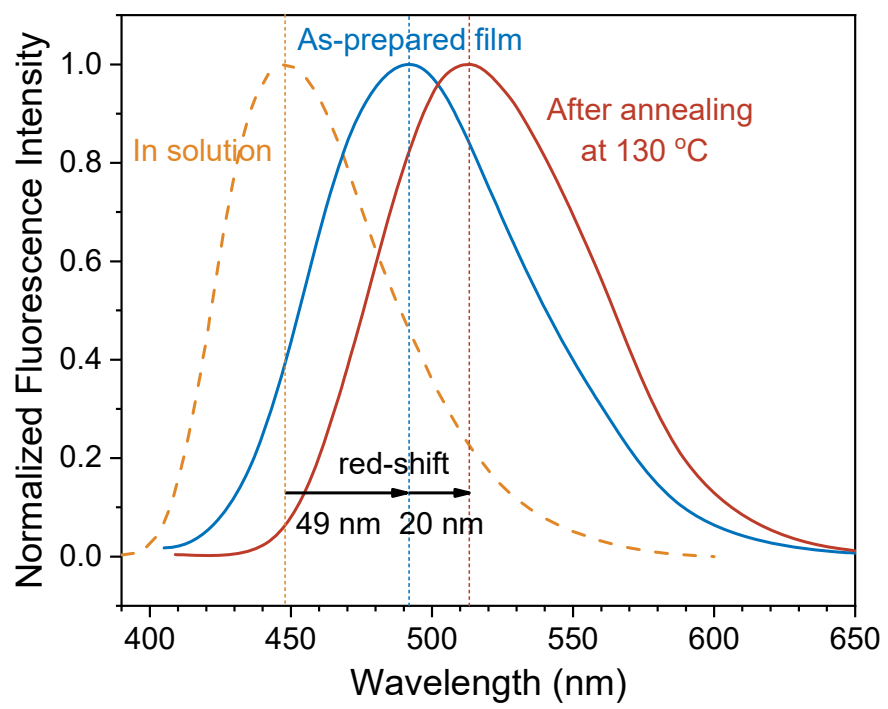

Figure S14. Normalized fluorescence spectra obtained from 9C6-amide-TCS in solution (yellow dashed line), or as-prepared film solid (blue solid line) or after annealing at $130{ }^{\circ} \mathrm{C}$ for several hours (red solid line). 


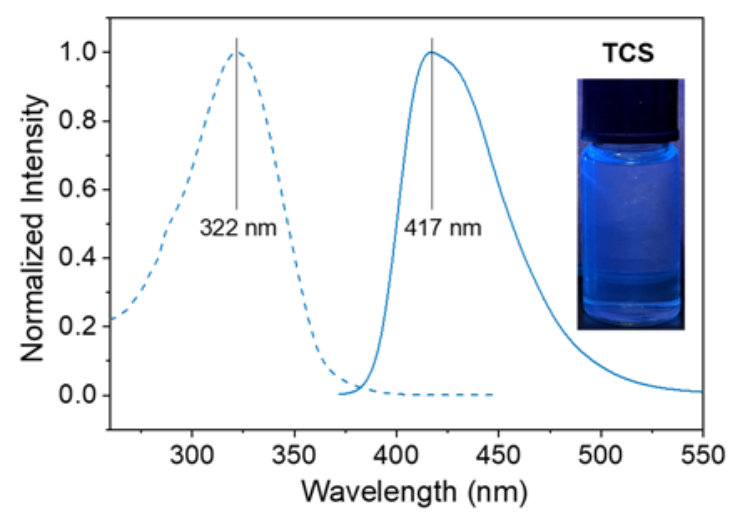

Figure S15. Normalized absorption and emission spectra collected from TCS compound in tetrahydrofuran (THF) solution.

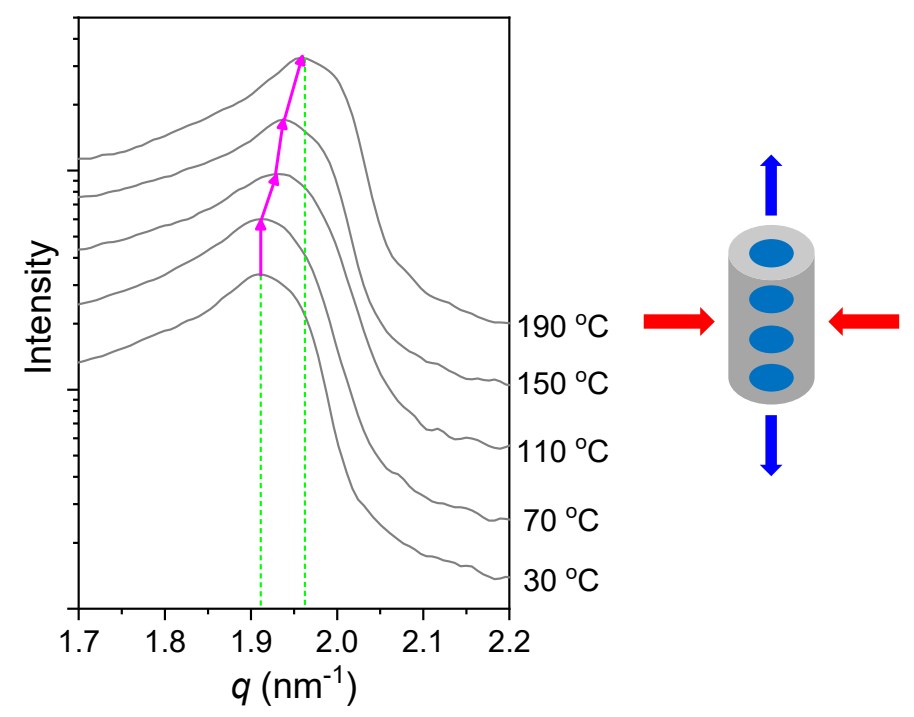

Figure S16. Temperature dependent small-angle XRD profiles collected from 9C6-amide-TCS, with only the relevant (100) diffraction shown between 1.7 and $2.2 \mathrm{~nm}^{-1}$. The peak is gradually shifted to the wide-angle region with increasing temperature, indicating the columnar cross-section area decreased with increasing temperature (red arrow) likely due to the modulation of the aliphatic shell, which therefore must give rise to extension deformation along the column (blue arrow) to satisfy the reasonable density, leading to increased interdisc distance and weakened $\pi$-electronic coupling interactions. 


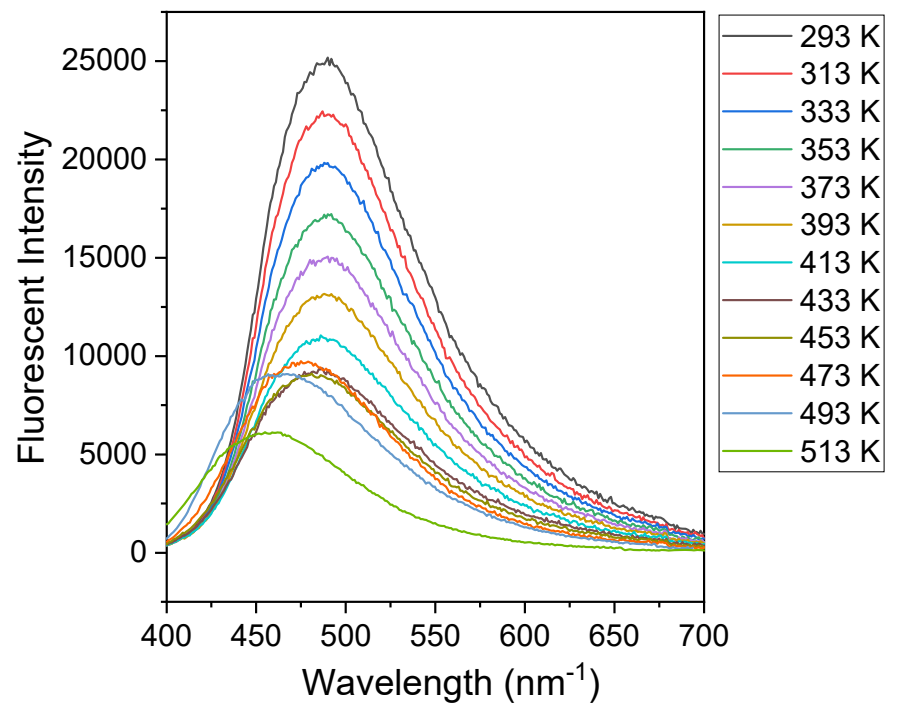

Figure S17. Temperature dependent emission spectra of 9C6-amide-TCS at indicated temperatures upon cooling process.

\section{Concentration Dependent Self-Assemblies and Luminescence Tuning Behavior}
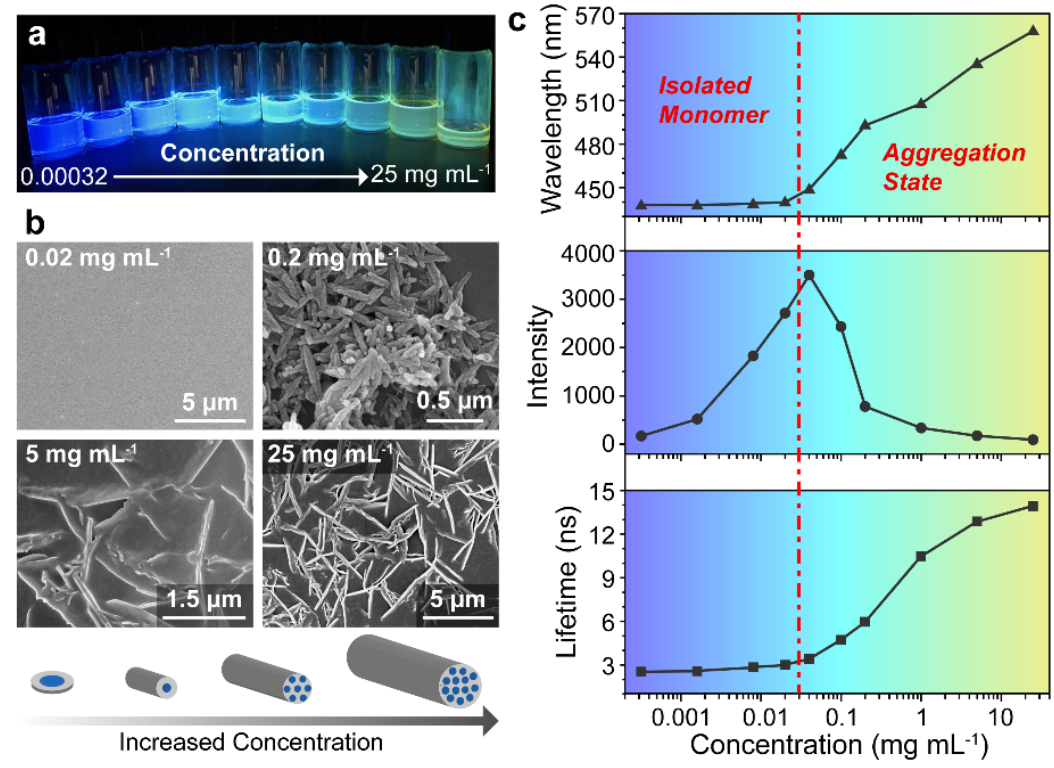

Figure S18. Concentration dependent assemblies of 9C6-amide-TCS in toluene solution and their influence on the emission properties. (a) Fluorescence images taken under $365 \mathrm{~nm}$ UV light with variant concentrations. (b) SEM images obtained from solutions at indicated concentrations. (c) The fluorescence wavelength maximum, relative intensity, and lifetime as a function of concentrations. 

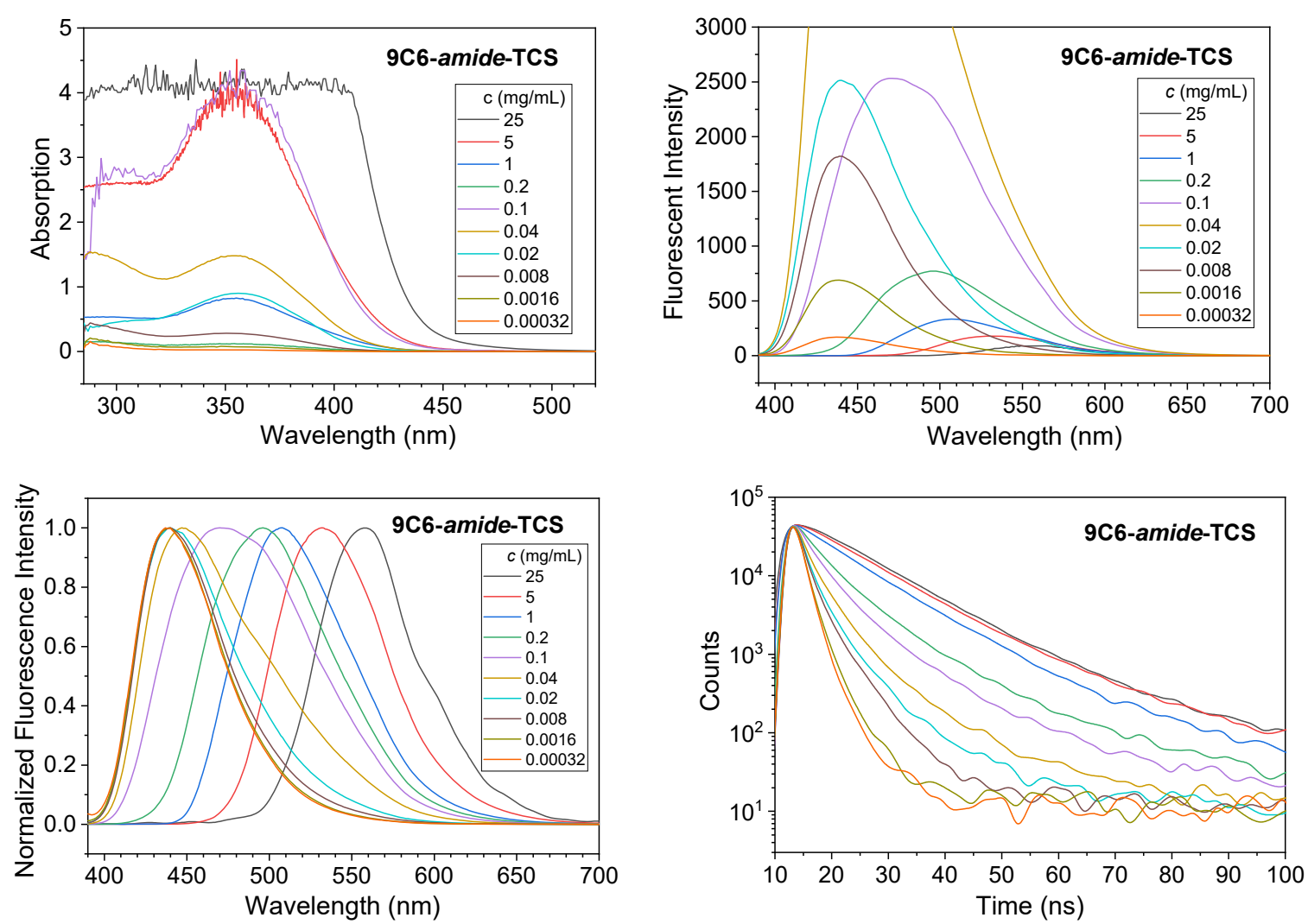

Figure S19. UV-vis absorption and fluorescent emission spectra of 9C6-amide-TCS in toluene solution at variant concentrations. Note that, the UV-vis experiments were performed with a $1 \mathrm{~cm}$ width cell for concentrations lower than $0.1 \mathrm{mg} \mathrm{mL}^{-1}$, while a $0.01 \mathrm{~cm}$ width cell was used for higher concentrations of $0.2 \sim 25 \mathrm{mg} \mathrm{mL}^{-1}$.
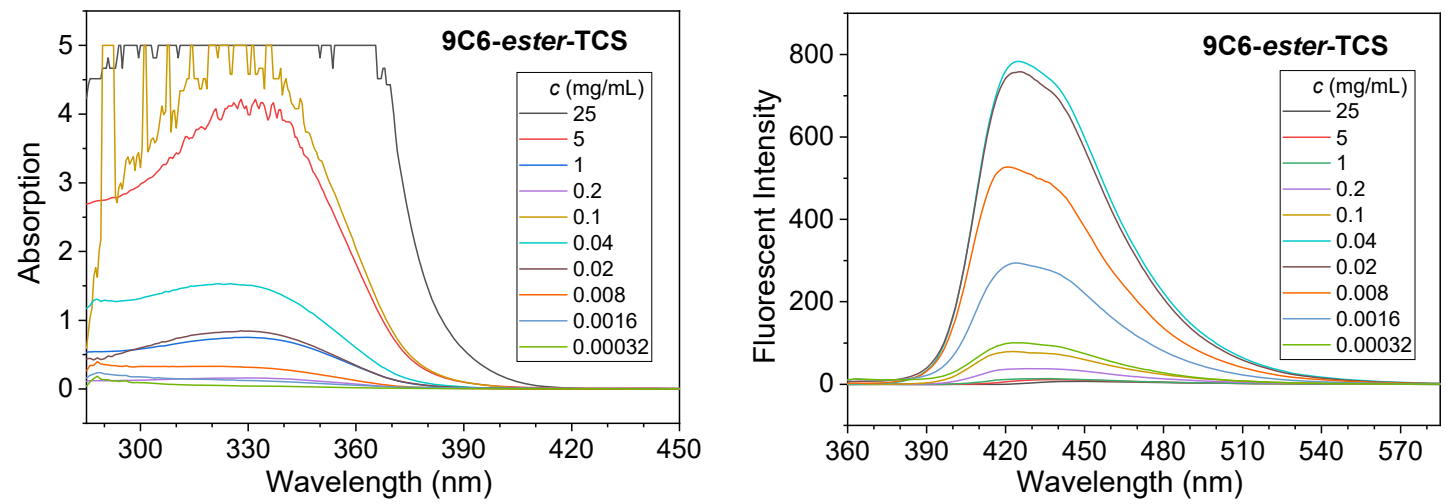

Figure S20. UV-vis absorption and fluorescent emission spectra of 9C6-ester-TCS in toluene solution at variant concentrations. Note that, the UV-vis experiments were performed with a $1 \mathrm{~cm}$ width cell for concentrations lower than $0.1 \mathrm{mg} \mathrm{mL}$, while a $0.01 \mathrm{~cm}$ width cell was used for higher concentrations of $0.2 \sim 25 \mathrm{mg} \mathrm{mL}^{-1}$. 
Structural and photophysical studies of 9C6-amide-TCS in condensed state have manifested a fascinating thermochromic luminescence behavior thanks to the hydrogen bond assisted regulation of intracolumnar $\pi-\pi$ interactions. Thus, it is also expected that it also possesses self-organizing properties in proper solvents, as such kind of trisamide discotic compounds have been widely studied to assemble into various aggregates in solutions due to the intermolecular $\pi$ - $\pi$ stacking and multivalent hydrogenbonding interactions. ${ }^{2,3}$ The fluorescence images in toluene solution (Figure S18a) clearly showed a smooth color change from blue to yellow with an increase of concentration from 0.00032 to $25 \mathrm{mg}$ $\mathrm{mL}^{-1}$, which pointed to the formation of $\pi-\pi$ interaction involved assemblies. SEM experiments (Figure $\mathrm{S} 18 \mathrm{~b})$ demonstrated the aggregates in columnar morphology, and these columnar aggregates became longer and thicker with the increase of concentration. Unlike the conventional trisamide discotic compounds that usually formed gels, the 9C6-amide-TCS solution only became viscous even at a high concentration of $25 \mathrm{mg} \mathrm{mL}^{-1}$ without gelation, probably because of the relatively large and nonplanar TCS core against long enough columns formation to induce cross-linked gels. To gain further insight into the assemblies induced fluorescence tuning behavior, concentration-dependent spectroscopic experiments were performed (Figure S19). The absorption maximum all appeared at $355 \mathrm{~nm}$ independent on the concentrations, resembling that in orderly assembled columnar LC solid. Figure S18c summarized the fluorescence wavelength, relative intensity, and lifetime as a function of concentrations, which was easy to divide into two distinct regions from the changing trend of the curves. In the left blue area, it was obvious shown the fluorescence maximum wavelength and lifetime stayed around $439 \mathrm{~nm}$ and $2.5 \mathrm{~ns}$, respectively, and exhibited no distinct change with increasing concentration, while the relative intensity significantly increased, suggesting isolated monomer or weak aggregation state. With the concentrations further increasing until $0.04 \mathrm{mg} \mathrm{mL}^{-1}$ by entering into the right cyan-yellow area, the fluorescence maximum wavelength began to bathochromically shift from $439 \mathrm{~nm}$ to $558 \mathrm{~nm}$ with simultaneously decreased intensity and extended lifetime as the concentration progressively increased to $25 \mathrm{mg} \mathrm{mL}^{-1}$. This was probably resulting from the gradual change of intracolumnar interdisc $\pi-\pi$ interactions upon concentration-dependent aggregation process that induced variant degree of electronic coupling between the chromophores in excited state of hydrogen-bonded aggregates. SEM (Figure S18b) revealed the growth of the size of the hydrogenbonded aggregates with increased concentration, which may increase the possible electron transfer in the $\pi$-stacks of TCS in the excited state, thus giving rise to progressively redshifted emission band, 
prolonged decay lifetime, and reduced efficiency. Moreover, there was no obvious concentrationdependent fluorescence color change for 9C6-ester-TCS (Figure S20), manifesting the significance of hydrogen bond on the assembly induced fluorescence tuning behavior. Therefore, the development of hydrogen-bonded columnar aggregates along the $\pi$-stacking direction gave rise to the presence of concentration-dependent emission band, which enabled continuous tuning of the luminescence properties.

\section{References for Supporting Information}

(1) Mu, B.; Quan, X.; Zhao, Y.; Li, X.; Tian, W. Fluorophore Core-Engineered Supramolecular Discotic Columnar Liquid Crystals with Tunable Fluorescent Behavior. Mater. Chem. Front. 2019, 3, 1671-1677.

(2) Anetai, H.; Wada, Y.; Takeda, T.; Hoshino, N.; Yamamoto, S.; Mitsuishi, M.; Takenobu, T.; Akutagawa, T. Fluorescent Ferroelectrics of Hydrogen-Bonded Pyrene Derivatives. J. Phys. Chem. Lett. 2015, 6, 1813-1818.

(3) Kulkarni, C.; Meijer, E. W.; Palmans, A. R. A. Cooperativity Scale: A Structure-Mechanism Correlation in the Self-Assembly of Benzene-1,3,5-tricarboxamides. Acc. Chem. Res. 2017, 50, 19281936. 